\title{
Failure of pyridoxine to reduce drug-induced dyskinesias
}

\author{
GEORGE E. CRANE, IBRAHIM S. TUREK, AND ALBERT A. KURLAND \\ From the Psychopharmacology Research Branch, National Institute of Mental Health, Chevy Chase, Maryland, \\ Maryland Psychiatric Research Center and Friends of Psychiatric Research, Baltimore, Maryland, and \\ Maryland Psychiatric Research Center, Baltimore, Maryland, U.S.A.
}

SUMMARY The use of pyridoxine seems to be ineffective in reducing tardive dyskinesia.

Patientsaffected by Parkinsonism respond favourably to L-dopa, but a sizeable proportion of these subjects develops troublesome dyskinesias (Cotzias, 1969; Cotzias, Papavasiliou, and Gellene, 1969; Yahr, Duvoisin, Schear, Barrett, and Hoehn, 1969). These side-effects, which were first described by Papavasiliou, Gellene, and Cotzias (1969) are often of a ballistic type but also consist of grotesque facial grimacing, protrusion of the tongue, and rhythmic movements of the mouth resembling the tardive dyskinesias induced by drugs.

Investigators from Columbia University recently made an unexpected observation-namely, that pyridoxine (Vitamin $\mathrm{B}_{6}$ ) neutralizes the effects of L-dopa administered to patients with Parkinsonism (Yahr and Duvoisin, 1969; Duvoisin, Yahr, and Cole, 1970). Symptoms such as bradykinesia and rigidity which were relieved by L-dopa reappear within a short period of time after the administration of pyridoxine. As Parkinsonian symptoms return, the hyperkinesias diminish in intensity and finally are completely abolished.

The literature seems to indicate that there is a reciprocal relationship between tardive dyskinesia and drug-induced Parkinsonism, in that substantial bradykinesia is seldom associated with pronounced hyperkinesias and vice versa (Crane, 1969). In an effort to reduce the motor abnormalities of tardive dyskinesia and achieve a better tolerated state of reduced motility it was decided to try pyridoxine on a selected sample of patients. The rationale and theoretical background for testing the therapeutic potential of pyridoxine on patients afflicted with tardive dyskinesia were rather tenuous. Nevertheless, we felt that this effort was justified, first, because there is practically no hazard in administering pyridoxine and, second, because the tardive dyskinesias so far have not responded to any type of treatment.

\section{PILOT STUDY}

A preliminary study was done on two mental patients exhibiting typical bucco-lingual-masticatory disorders and other dyskinesias; one patient had had no psychotropic medication for one year and the other was on perphenazine plus benzhexol (Artane) for three months before pyridoxine treatment. There were no changes in symptomatology after 10 days of treatment with $300 \mathrm{mg}$ pyridoxine.

\section{METHODS}

PATIENTS Nine additional patients were selected for the study. Eight were on the following drugs: chlorpromazine 100 to $600 \mathrm{mg} /$ day (two patients); perphenazine $12 \mathrm{mg}$ (two); proketazine $50 \mathrm{mg}$ (one); thioridazine $150 \mathrm{mg}$ (two); one patient had no medication. Three patients also received trihexyphenidyl and one imipramine. Dyskinesias, which were fairly conspicuous, were as follows: the bucco-lingual-masticatory syndrome (eight patients), dyskinesia of the upper extremity (five), dyskinesia of the lower extremity with postural instability (four), and dystonia (one). Some had more than one of the above symptoms; in addition, tremor of the upper extremities was present in three patients, amimia in one, and generalized bradykinesia in one.

PROCEDURE Pyridoxine in doses of $100 \mathrm{mg}$ t.i.d. was administered for 14 days. On the eighth day the administration of all neuroleptics and ancillary drugs was discontinued. Thus patients received only pyridoxine during the last week of the study. The patients were rated for dyskinesia before the administration of pyridoxine and then two, eight, and 14 days later. Each assessment was made without knowledge of the results of previous evaluations.

\section{RESULTS}

The symptomatology of five patients was unchanged. One patient became symptom free (neurologically), another was relieved of postural instability but 
developed a pronounced respiratory tic. In two patients who exhibited hyperkinetic as well as hypokinetic manifestations no change in the former sign was observed, but in one patient amimia disappeared and in the other bradykinesia and tremorcleared completely only after all neuroleptics were withdrawn. In conclusion, pyridoxine had no therapeutic effects on tardive dyskinesia except for one patient whose improvement is questionable, because he had exhibited some fluctuation in his symptoms during a 12 month observation period before treatment with pyridoxine. It is of interest that in at least two cases pyridoxine did not prevent the reversal of Parkinsonism after withdrawal of neuroleptic drugs.

\section{REFERENCES}

Cotzias, G. C. (1969). L-Dopa in Parkinson's disease. Hosp. Pract., No. 9, 35-41.
Cotzias, G. C., Papavasiliou, P. S., and Gellene, R. (1969). Modification of Parkinsonism. Chronic treatment with L-dopa. New Engl.J. Med., 280, 337-345.

Crane, G. E. (1969). Discussion of paper by R. Degkwitz. In Psychotropic Drugs and Dysfunctions of the Basal Ganglia. A Multidisciplinary Workshop. Edited by G. E. Crane, and R. Gardner, p. 30. U.S. Government Printing Office, Washington.

Duvoisin, R. C., Yahr, M. D., and Cole, L. (1970). Reversal of the 'Dopa Effect' in parkinsonism by pyridoxine. (In press.)

Papavasiliou, P. S., Gellene, R., and Cotzias, G. C. (1969). Modification of parkinsonism: dyskinesias accompanying treatment with dopa. In Psychotropic Drugs and Dysfunctions of the Basal Ganglia. A Multidisciplinary Workshop. Edited by G. E. Crane and R. Gardner. U.S. Government Printing Office, Washington.

Yahr, M. D., and Duvoisin, R. C. (1969). The treatment of parkinsonism with L-dopa. 9th International Congress of Neurology October 20-27, 1969, New York, N.Y. Summarized in Drug Topics Oct. 13, 1969, p. 17.

Yahr, M. D., Duvoisin, R. C., Schear, M., Barrett, R. E., and Hoehn, M. (1969). Treatment of Parkinsonism with Levodopa. Arch. Neurol. (Chic.), 21, 343-354. 